\title{
Japanese budget boosts science funding
}

[TOКYO] Japan's largest ever budget, aimed at reviving the nation's ailing economy through increased public spending, includes a generous 8.1 per cent boost in expenditure on science, with a strong emphasis on basic research.

The budget for the 1999 fiscal year, which begins on 1 April, takes overall science spending across all ministries and agencies to $¥ 963$ billion (US $\$ 8.5$ billion), with large increases for life sciences in particular. Also featured are support for creating new businesses through 'commercially applicable research', and the promotion of collaborative research between universities and industry.

The total government budget of $¥ 81.9$ trillion - an increase of 5.4 per cent from the previous year and the highest growth rate in 20 years - was approved by the Cabinet on 25 December. The increase in science expenditure is in line with the five-year plan for science and technology, under which the government pledged to double the nation's research spending between 1996 and 2001.

The budget for the Science and Technology Agency (STA) has grown by 4.1 per cent from last year, as a result of increased support for brain and genome research, especially with last year's opening of the Genome Sciences Centre, backed by the Institute of Physical and Chemical Research. Spending on nuclear and space research was kept down so more funding can be allocated to basic research in other areas, according to STA.

Spending on space development will increase by 2.6 per cent by the last-minute addition of funding for a reconnaissance satellite to improve Japan's ability to gather security information, following last year's firing of a North Korean missile over Japanese territory (see Nature 396, 401; 1998).

The satellite will be allocated $¥ 11.3$ billion in 1999 , with $¥ 6.8$ billion going to STA (included in the space development budget), $¥ 2.2$ billion to the Ministry of International Trade and Industry (MITI), ¥1.4 billion to the Cabinet secretariat, and $¥ 0.9$ billion to the post and telecommunications ministry.

STA will also gain an extra $¥ 2.7$ billion to produce SELENE, a lunar probe jointly developed by MITI and the Ministry of Post and Telecommunications. Although the overall budget for the Ministry of Education, Science, Sports and Culture (Monbusho) has increased by only 1.4 per cent, its spend-

\begin{tabular}{|c|c|c|}
\hline $\begin{array}{l}\text { Highlights of Japan } \\
\text { Budget } 1999 \text { (in billi } \\
\text { Science and Techn }\end{array}$ & $\begin{array}{l}\text { Ice and } \\
\text { US\$1 } \\
\text { gency }\end{array}$ & (3) \\
\hline Total budget & 770.7 & $+4.1 \%$ \\
\hline General R\&D budget & 612.2 & $+4.6 \%$ \\
\hline Genome research & 11.9 & $+70.9 \%$ \\
\hline Brain research & 18.3 & $+30.8 \%$ \\
\hline Deep-sea drilling & 3.4 & $+453 \%$ \\
\hline Atomic energy & 187.2 & $-1.9 \%$ \\
\hline Space development & 187.2 & $+2.6 \%$ \\
\hline STA fellowships & 3.8 & $+5.5 \%$ \\
\hline
\end{tabular}

Ministry of Trade and Industry (MITI)

Total R\&D budget $\quad 508.1 \quad+3.1 \%$
Agency for Industrial Science and Technology 135.8 New Industry R\&D 44.3 $+6.7 \%$ Joint Research with universities Energy

3.6

49.1 $+58.9 \%$ $+7.0 \%$

\section{Ministry of Education, Science, Sports and} Culture (Monbusho)

\section{Grants in aid for scientific}

research

187.9 $+6.7 \%$

Japan Society for Promotion of Science

(postdoctoral fellowships) Joint research with industry Centre of excellence programme High-energy accelerator Neutrino oscillation ing for scientific research has grown by a comparatively generous 6.7 per cent.

The Long Baseline Neutrino Oscillation Experiment, carried out jointly by the Institute of Cosmic Ray Research at Tokyo University and Monbusho's High Energy Accelerator Research Organization (KEK), will gain $¥ 1$ billion, and high-energy accelerator research at KEK will receive $¥ 8.5$ billion. This is an increase of 372 per cent from last year, to cover the initial operating costs of Belle, a precision particle detector for studying B-mesons (Nature 396, 612; 1998).

The postdoctoral fellowship scheme under Monbusho, which aims to increase the number of Japan's postdoctoral researchers to 10,000 by the millennium, is expected to reach its target this year. Monbusho and STA will support an extra 1,304 postdocs in 1999, making 10,076 by the end of the fiscal year.

MITI's spending on research has gone up by 8.9 per cent from last year. Support for new venture businesses will receive a spending boost, especially at universities, following the passing of a law promoting collaboration between universities and industry.

The budget has yet to be approved by the Diet (Japan's parliament), but changes to science-related budgets are usually minimal.

This year's dramatic spending increase is in sharp contrast to last year's austere budget. This was drawn up under the Fiscal Structural Reform Act, which sought to cap spending commitments in order to control government deficits and promote budgetary restraint; the law has since been frozen.

While the 1999 budget is aimed at producing the government's projected economic growth - 0.5 per cent in gross domestic product by the next fiscal year - analysts are critical that it will be partly funded by $¥ 31$ trillion in government bonds, putting the nation deeper in debt.

AsakoSaegusa

\section{Software problem delays US spacecraft's meeting with asteroid}

[WASHINGTON] The Near-Earth Asteroid Rendezvous (NEAR) spacecraft, which was supposed to have begun orbiting the asteroid Eros next week, will meet up with it in February 2000 instead. The delay, which project managers say will not reduce the mission's scientific return, was caused by a software problem when the spacecraft's main engine was fired on 20 December.

NEAR - operated for the US space agency NASA by the Johns Hopkins University Applied Physics Laboratory (APL) - was designed to orbit the asteroid, photographing its surface, mapping minerals, and returning gravity data.

The manoeuvre on 20 December was intended to position the spacecraft to begin orbiting Eros. But when the engine fired, the acceleration triggered software designed to protect the spacecraft from uncontrolled motion. NEAR automatically aborted its engine burn and waited for a signal from the ground, ruining chances of a rendezvous with Eros this year.

Engineers switched to a contingency plan for an engine firing on 3 January and a rendezvous 13 months later. Another option, for a meeting with Eros in July, was scrapped because the command sequences had to be revised too quickly.

Tom Coughlin, the NEAR project manager at APL, says the software that triggers the abort modes will be reworked to avoid a similar mishap in the future. The spacecraft wasted about 30 per cent of its fuel during the aborted manoeuvre, but Coughlin says it still has enough to execute the full year-long study of Eros.

Managers want to keep open the option to land the spacecraft briefly on Eros after the main mission ends. Such an extension to the mission, which would have to be approved and funded by NASA, is still possible with the amount of fuel remaining.

The delay is likely to cost NASA millions of dollars, but has at least one benefit. Because the spacecraft was able to return images and take data on 23 December, scientists will have a better understanding of the asteroid's shape and mass when close manoeuvres begin next year. Tony Reichhardt 